DOI: 10.20472/IAC.2018.039.018

\author{
HANAN ISHAQUE \\ Alpen-Adria University Klagenfurt, Austria
}

\title{
EVALUATING THE IMPLICIT COST OF CO2 ABATEMENT WITH RENEWABLE ENERGY INCENTIVES IN PAKISTAN
}

\begin{abstract}
:
The use of renewable energy (RE) sources contributes to the sustainable development goals of climate change mitigation and access to clean and affordable energy. To diversify the electricity mix, reduce reliance on fossil-fuels and abate powers sector $\mathrm{CO} 2$ emissions, the Government of Pakistan developed a policy to incentivize RE deployment by offering upfront feed-in tariffs (FIT). This paper attempts to estimate the cost of $\mathrm{CO} 2$ emission abatement with RE incentives for solar and wind power plants for the period 2015-2020. The implicit cost of CO2 abatement defined as the ratio of net cost of RE to CO2 emissions avoided is estimated to be $\$ 116 / \mathrm{tCO} 2$ for wind and $\$ 78 / \mathrm{tCO} 2$ for solar power. The payment to generators guaranteed by FITs is a major determinant and explains the difference between the implicit abatement costs of solar and wind power. These estimates, however, are sensitive to the resources displaced by RE and the fuel prices. This study provides a framework to the policymakers for analysis of RE incentives recognizing the dynamic nature of the abatement cost metric and discusses policy implications in the light of the results.
\end{abstract}

\section{Keywords:}

CO2 abatement cost, renewable energy, feed-in tariff, Pakistan

JEL Classification: C54, E60, 013 